\title{
Instability Of Risk Loadings Of Industrial Stocks
}

Ling T. He (E-mail: linghe@mail.uca.edu), University of Central Arkansas

\begin{abstract}
By using the Flexible Least Squares (FLS) method, this study visibly shows the time variation paths of risk loadings for industrial stocks. Significant structural changes in time variation paths of risk loadings are verified by the OLS results and largely consistent with major economic and political events in the U.S. history.
\end{abstract}

\section{Introduction}

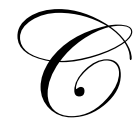
apital asset pricing issues have attracted numerous studies for more than three decades. According to the first important asset pricing theory, the Capital Asset Pricing Model (CAPM) of Sharpe (1964) and Lintner (1965), there is a positive linear relationship between expected stock returns and market betas. This single-factor model is facing theoretical challenges from the Arbitrage Pricing Theory (APT) developed by Ross (1976). The APT provides a theoretical framework to identify more macro factors that have significant explanatory power for stock returns (Roll and Ross, 1980; Chen, 1983; Bower, Bower, and Logue, 1984; Chen, Roll, and Ross, 1986; Goldenberg and Robin, 1991; Bower and Schink, 1994; and Elton, Gruber, and Mei, 1994). In recent years, more risk factors have been suggested in the literature. For example, in their studies about common risk factors in returns on common stocks, Fama and French $(1993,1995,1997)$ argue that there are three stock market factors, an overall market factor, a size factor (stock price times number of shares), and a book-to-market equity factor, that have a significant impact on stock returns. Furthermore, Fama and French (1997) point out that there is strong variation through time in the three factor risk loadings. How do factor risk loadings actually vary over time? That is, what are visible time variation paths of risk loadings? What are dynamic correlations between time-varying risk loadings? There are no clear answers to those questions in the literature.

To trace out time variation paths of risk loadings is essential to find solutions to those problems. First, changes of risk loadings over time can be visibly displayed in time variation paths. Therefore, structural switches in risk loadings or important sub-periods cannot be left out. Second, the visible continuous changes of risk loadings make it possible to identify important economic and political events responsible for big alterations in risk loadings in each major sub-period. Third, time variation curves of risk loadings also reveal time-varying correlations between risk loadings. A positive correlation between two risk loadings reflects their common responses to some fundamental economic or political events, while a negative correlation indicates opposite responses. The time variation paths can be detected by using the Flexible Least Squares (FLS) method developed by Kalaba and Tesfatsion (1988, 1989, and 1990).

The FLS technique is an effective tool for analyzing the instability of regression coefficients by showing the smooth changes of the coefficients over time. In order to smooth the volatile coefficients, the FLS approach releases the time-constant restriction on coefficient estimates in the Ordinary Least Squares (OLS) method and recursively estimates the time paths of the coefficients of a regression model. During the estimation process, the FLS approach tries to minimize both the squared residual measurement errors (squared regression errors) and the squared dynamic errors (squared coefficient variations). Therefore, the collection of all FLS sequential estimates of coefficients exhibits the efficient attainable tradeoffs between residual measurement errors and residual dynamic errors. The time paths of coefficient esti- 
mates traced out by the FLS reveal unanticipated qualitative movements in each coefficient estimate at dispersed points in time, consequently, illuminate all major changes in coefficients over time. ${ }^{1}$

In order to push the research on factor risk loadings one step further, this study depicts time variation paths of risk loadings based on the three-factor model of Fama and French (1993) by using the FLS method. Furthermore, significant political and economic events are used to explain time variation paths of risk loadings which are verified by the OLS results.

The remainder of this paper is organized as follows. Section I describes the FLS method and data, Section II presents the empirical results, and Section III contains the concluding comments.

\section{The FLS Method And Data}

The following general regression model can demonstrate the FLS method:

$Y_{t}=X_{t} b_{t}+e_{t}, t=1, \ldots, T$,

where $X_{t}=\left(X_{t 1}, \ldots, X_{t k}\right)$ and $b_{t}$ are $(K x 1)$ vectors, the FLS approach specifies the time paths $b_{1}, \ldots b_{T}$ of the coefficient vectors which minimize the incompatibility loss function (the sum of squared residual measurement error plus the sum of squared residual dynamic error):

$C(b ; \mu, T)=\sum_{t=1}^{T}\left(Y_{t}-{ }^{\prime} X_{t} b_{t}\right)^{2}+\mu \sum_{t=1}^{T-1}\left(b_{t+1}-b_{t}\right)^{\prime} D\left(b_{t+1}-b_{t}\right)$,

where $\mu$ is a pre-chosen positive constant and $\mathrm{D}$ is a fixed dynamic scaling $(\mathrm{K} \times \mathrm{K})$ matrix. Like Tesfatsion and Veitch (1990), $\mathrm{D}$ is defined as a diagonal matrix with ith diagonal term $d_{i i}=\left(X_{1 i}^{2}+X_{T i}^{2}\right) / T, \mathrm{t}=1, \ldots, \mathrm{T}$. Therefore, multiplication of a regressor by a constant cannot cause any changes in the shape of the time path of the corresponding coefficients. In order to set the smoothing weight between zero and one, that is, $\mu \in(0,1)$, the incompatibility function can be rewritten as the following:

$C(b ; \mu, T)=\frac{1}{1-\mu}\left[(1-\mu) \sum_{t=1}^{T}\left(Y_{t}{ }^{-}{ }^{\prime} X_{t} b_{t}\right)^{2}+\mu \sum_{t=1}^{T-1}\left(b_{t+1}-b_{t}\right)^{\prime} D\left(b_{t+1}-b_{t}\right)\right]$.

The FLS approach is essentially descriptive. Therefore, no stochastic assumptions are necessary. Nevertheless, Lutkepohl (1993) proves the potential stochastic frameworks for the FLS method.

The size of $\mu$ represents the weight on the dynamic specification and therefore, plays an important role in the coefficient variation. As $\mu$ approaches zero, the squared residual measurement error can generally be reduced to zero and the corresponding value for the squared residual dynamic error will be relatively large. Thus, $b_{t}$ tends to become more volatile as the value of $\mu$ decreases. On the other hand, the squared residual measurement error is minimized (subject to the squared residual dynamic error equal to zero), when $\mu$ becomes arbitrarily large. That is, the $b_{t}$ become con-

\footnotetext{
1 Other econometric techniques may be able to identify structural switches, but cannot generate smooth time variation paths for individual coefficients. For example, the Cusum and Cusum of Squares tests developed by Brown, Durbin, and Evans (1975) can be used to find switch points for a multi factor regression model. Nevertheless, this method focuses only on the residuals of the OLS regression model, therefore, rules out any possibilities to observe and analyze changes in individual coefficients over time. The rolling regressions may produce time-varying coefficients. However, the results may be too volatile to generate smooth time variation paths of coefficients.
} 
stant and approach the OLS solution with a single time-invariant coefficient vector. However, the appropriate size of $\mu$ is verified by the OLS results for sub-periods suggested by the FLS time variation paths of coefficients.

This study uses time series data that covers the period of February 1934 through December 1997. There is no specific reason, other than the availability of data, for the selected sample period. The data set includes the following monthly return indices:

$\mathrm{R}_{\mathrm{m}} \quad=$ the monthly returns on the NYSE/ASE/NASDAQ value-weighted index (CRSP Stock Files). SMB (small minus big) $=$ the monthly returns on the mimicking portfolio for the common size factor in stock returns. This is the difference between the simple averages of the percent returns on the three smallstock and the three big-stock portfolios with similar average book-to-market ratios. See Fama and French (1997) for a detailed discussion of the construction of the series ${ }^{2}$.

HML (high minus low) = the monthly returns on the mimicking portfolio for the common book-to-market equity factor in stock returns. This is the difference between the simple averages of the percent returns on the two high- and two low-book-to-market equity portfolios with similar average size. See Fama and French (1997) for a detailed discussion of the construction of the series.

Rf $=$ the one-month Treasury bill rate observed at the beginning of the month (Stocks, Bonds, Bills, and Inflation 1998 Yearbook, Ibbotson Associates).

Ri = the monthly returns on the S\&P Industrial Stock Value-Weighted Index. The index consists of 86 industrial groups or 376 companies as of December 1997.

Essentially, the FLS approach is a detailed time-series analysis. It is not feasible to perform the FLS analyses on multiple series of data in a single project. Therefore, only a general industrial stock portfolio is analyzed in this study.

\section{Results}

\subsection{Summary Statistics}

Table 1 provides some descriptive statistics for excess returns of industrial stocks and factor risk premiums. The Ordinary Least Squares (OLS) and the Flexible Least Squares (FLS) regression estimates of the three-factor model of Fama and French $(1993,1995$, and 1997) for the entire sample period are summarized in Table 2. The OLS results indicate that the coefficient of $\left(\mathrm{R}_{\mathrm{m}}-\mathrm{R}_{\mathrm{f}}\right)$, b, plays a very significant role in explaining variation of excess returns of industrial stocks. The coefficient of SMB, s, has a size of 0.24 with a high t-statistic of 6.09. While the coefficient of HML (h) is only about 0.01 it is statistically indifferent from zero. This suggests that HML may not be a relevant explanatory variable to industrial stocks for the period of February 1934 to December 1997.

The FLS results reveal the similar picture. The coefficient average for $b$ is 0.49 combined with a slightly higher standard deviation and coefficient of variation, 0.16 and 0.33 , respectively. The coefficient average for $\mathrm{s}$ is 0.32 . The instability of $s$ is close to that of $b$. It is evidenced by a standard deviation of 0.15 and a coefficient of variation of 0.48 for s. Compared with the OLS estimate, the magnitude of coefficient mean of $\mathrm{h}$ is sizable, 0.19. Although its standard deviation is as the same as the one for $\mathrm{s}$, its coefficient variation (8.17) is much larger than that for both $\mathrm{b}$ and s. It indicates that $h$ displays the highest volatility for every percent of returns. Overall, the standard deviations for $b, s$, and $h$ are substantially lower than that for $\left(\mathrm{R}_{\mathrm{m}}-\mathrm{R}_{\mathrm{f}}\right.$ ), SMB, and HML (Table 1). It is in line with Fama and French's (1997) finding that risk loadings are more stable than risk premiums.

The smoothing weight, $\mu$, used in the FLS estimation is 0.999. It is an appropriate weight that generates the FLS estimates which can be verified by the OLS method. Since the FLS method yields a series of coefficients for each independent variable, it is possible to explore relationships among different variable coefficients. Results from the correlation matrix of FLS coefficients unequivocally indicate a quite strong negative correlation between $\mathrm{b}$ and $\mathrm{s}$. The coefficient of correlation is -0.54 . This is in opposite to the correlation $(0.35)$ between $\left(\mathrm{R}_{\mathrm{m}}-\mathrm{R}_{\mathrm{f}}\right)$ and SMB. Compared with the correla-

\footnotetext{
2 Thanks go to Eugene Fama for providing the SMB and HML data.
} 
tion (-0.01) between $\left(R_{m}-R_{f}\right)$ and HML, the negative correlation (-0.22) between risk loadings of $b$ and $h$ is much stronger. The correlation between $\mathrm{s}$ and $\mathrm{h}$ is very weak. The coefficient of correlation is as small as -0.09 . However, it is still in contrast to the correlation (0.06) between SMB and HML. Overall, the correlations between risk loadings are negative and stronger than those between risk premiums.

Table 1

Descriptive Statistics For The Factor Risk Premiums And Excess Returns Of Industrial Stocks (In Percent): February 1934 - December 1997

The return series here and in all following tables are defined as follows. $R_{i}-R_{f}$ is the difference between monthly valueweighted returns for industrial stocks and the one-month Treasury bill rate. $R_{M}-R_{f}$ is the difference between NYSE/ASE/NASDAQ monthly value-weighted returns and the one-month Treasury bill rate. As Fama and French (1993, 1995, and 1997), SMB (small minus big) represents monthly returns on the mimicking portfolio for the common size factor; and HML (high minus low) reflects monthly returns on the mimicking portfolio for the common book-to- market equity factor. The sample size is 767 months.

\begin{tabular}{|cccccccc|}
\hline & & & \multicolumn{4}{c|}{ Correlations } \\
\cline { 5 - 8 } Variable & Mean & Std. Dev. & Std. Error & $\mathbf{R}_{\mathbf{i}}-\mathbf{R}_{\mathbf{f}}$ & $\mathbf{R}_{\mathbf{M}}-\mathbf{R}_{\mathbf{f}}$ & SMB & HML \\
\hline $\mathrm{R}_{\mathrm{i}}-\mathrm{R}_{\mathrm{f}}$ & 0.37 & 3.76 & 0.14 & 1.00 & & & \\
$\mathrm{R}_{\mathrm{M}}-\mathrm{R}_{\mathrm{f}}$ & 0.71 & 4.52 & 0.16 & 0.66 & 1.00 & 1.00 & \\
$\mathrm{SMB}$ & 0.17 & 2.71 & 0.10 & 0.38 & 0.35 & -0.01 & 0.06 \\
$\mathrm{HML}$ & 0.45 & 2.57 & 0.09 & 0.01 & -0.00 \\
\hline
\end{tabular}

Table 2

The Ordinary Least Squares (OLS) And Flexible Least Squares (FLS) Regression Estimates: February 1934 - December 1997

$R_{i}-R_{f}=a_{i}+b_{i}\left[R_{M}-R_{f}\right]+s_{i} S M B+h_{i} H M L+e_{i}$

The monthly return series, $R_{i}-R_{f}, R_{M}-R_{f}, S M B$, and HML, are described in Table 1 . The regression $R^{2}$ are adjusted for degrees of freedom. The following FLS estimates are reported: $\mathrm{m}(\mathrm{a}), \mathrm{m}(\mathrm{b}), \mathrm{m}(\mathrm{s})$, and $\mathrm{m}(\mathrm{h})$ are coefficient means for $\mathrm{a}, \mathrm{b}, \mathrm{s}$, and $\mathrm{h}, \mathrm{re}-$ spectively; sd(a), sd(b), sd(s), and sd(h) are standard deviations for a, b, s, h, respectively; cv(a), cv(b), cv(s), and cv(h) are coefficient of variations for $\mathrm{a}, \mathrm{b}, \mathrm{s}, \mathrm{h}$, respectively. The smoothing weight, $\mu$, used in the FLS estimation is 0.999 .

\begin{tabular}{|c|c|c|c|c|c|c|c|c|}
\hline \multicolumn{4}{|c|}{ OLS Estimates } & \multicolumn{5}{|c|}{ t-Statistics } \\
\hline $\mathbf{a}$ & b & $\mathbf{s}$ & $\mathbf{h}$ & $\mathbf{t}(\mathbf{a})$ & $\mathbf{t}(\mathbf{b})$ & $t(s)$ & $\mathbf{t}(\mathbf{h})$ & $\mathbf{R}^{2}$ \\
\hline-0.03 & 0.50 & 0.24 & 0.01 & -0.30 & 21.11 & 6.09 & 0.38 & 0.46 \\
\hline
\end{tabular}

\begin{tabular}{|c|c|c|c|c|c|c|c|c|c|c|c|}
\hline \multirow[b]{2}{*}{$\mathbf{m}(\mathbf{a})$} & \multirow[b]{2}{*}{$\mathbf{m}(\mathbf{b})$} & \multirow[b]{2}{*}{$\mathbf{m}(\mathbf{s})$} & \multirow[b]{2}{*}{$\mathbf{m}(\mathbf{h})$} & \multirow[b]{2}{*}{$\operatorname{sd}(\mathbf{a})$} & \multicolumn{2}{|c|}{ FLS Estimates } & \multirow[b]{2}{*}{$\operatorname{sd}(h)$} & \multirow[b]{2}{*}{$\operatorname{cv}(\mathbf{a})$} & \multirow[b]{2}{*}{$\operatorname{cv}(b)$} & \multirow[b]{2}{*}{$\operatorname{cv}(s)$} & \multirow[b]{2}{*}{$\operatorname{cv}(\mathbf{h})$} \\
\hline & & & & & sd(b) & $\operatorname{sd}(s)$ & & & & & \\
\hline-0.06 & 0.49 & 0.32 & 0.19 & 0.26 & 0.16 & 0.15 & 0.15 & -4.19 & 0.33 & 0.48 & 8.17 \\
\hline
\end{tabular}

\begin{tabular}{|cccc|}
\hline \multicolumn{5}{c|}{ Correlation Matrix Of FLS Coefficients } \\
\hline $\mathrm{b}$ & 1.00 & & \\
$\mathrm{~s}$ & -0.54 & 1.00 & 1.00 \\
$\mathrm{~h}$ & -0.22 & -0.09 & $\mathrm{~h}$ \\
& $\mathrm{~b}$ & $\mathrm{~s}$ & \\
\hline
\end{tabular}




\subsection{Time Variation Paths Of Risk Loadings (Sensitivities)}

Time variation paths are the result of graphical presentations of series of the FLS coefficients for independent variables. Figure 1 shows time variation paths of the stock market, SMB, and HML sensitivities from the three-factor model. Two interesting observations about time variation paths of the stock market and SMB can immediately be made. First, the time variation path of $b$ is opposite to that of $s$ for most time. That is, the negative correlation between $b$ and $s$ reported in Table 2 has graphically been reflected in Figures 1. Second, while the time variation path of $b$ is always above the zero level, the time variation path of $\mathrm{s}$ reaches the near-zero levels in some periods. It means that magnitude of $\mathrm{s}$ is close to zero in some years. Based on these two observations, the entire sample period can be broken up into the following seven sub-periods: (i) 2/34-12/54 is based on a negative correlation between $b$ and $s$ and a large size of s; (ii) 1/5512/65 contains a negative correlation and a trivial magnitude of s; (iii) 1/66-12/72 includes a negative correlation and a significant size of s; (iv) 1/73-6/80 includes a positive correlation and a sizable s; (v) 7/80-12/90 is based on a negative correlation and a big s; (vi) 1/91-12/92 is based on a positive correlation and a large s; and (vii) 1/93-12/97 contains a less strong positive correlation and an insignificant $\mathrm{s}$.

Figure 1: The FLS Time Variation Paths Of Risk Loadings In The Three-Factor Model

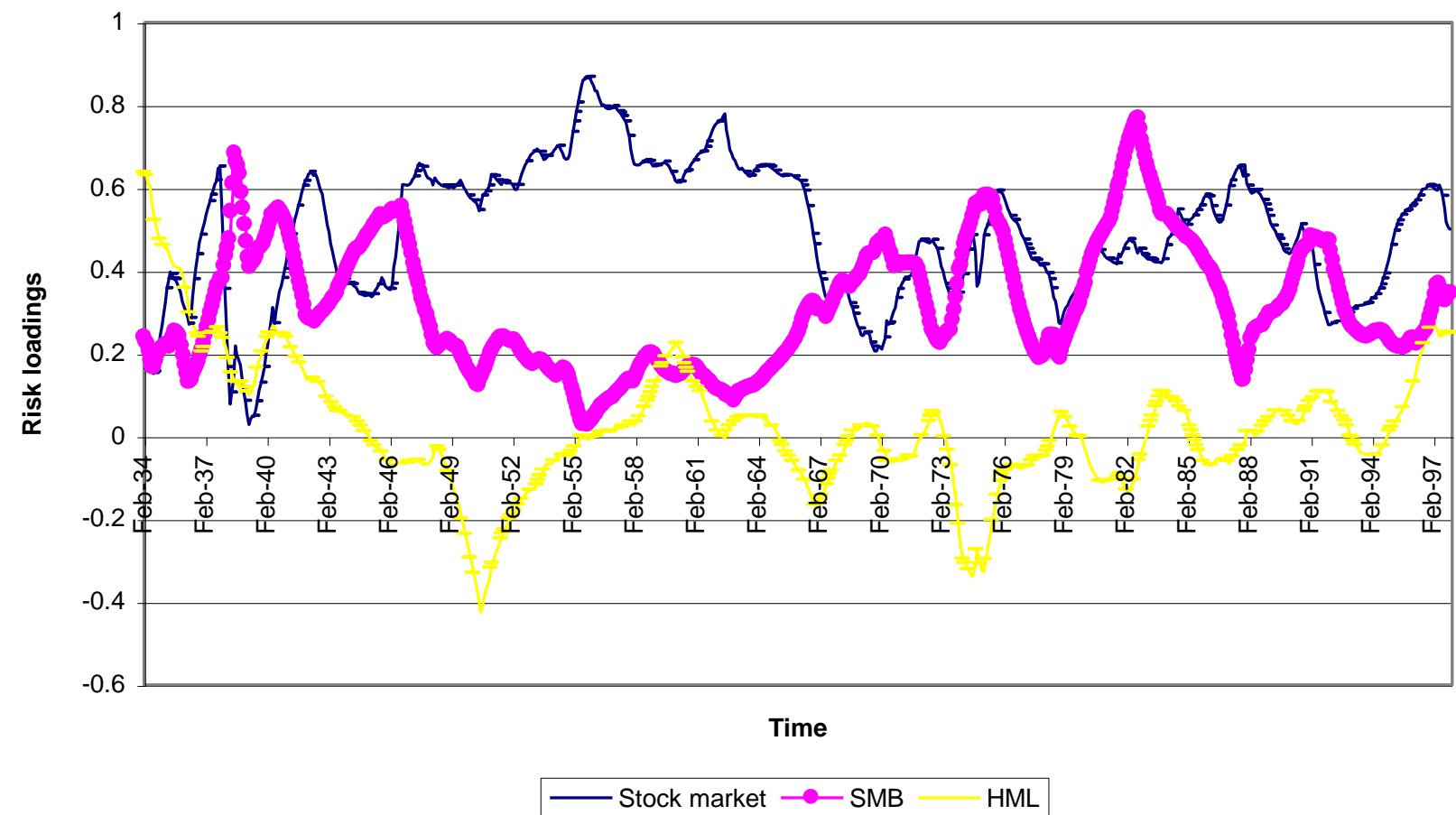

The strong negative correlation between $\mathrm{b}$ and $\mathrm{s}$ suggests that a fundamental economic or political change may explain changes in both $\mathrm{b}$ and $\mathrm{s}$. In addition, since $\mathrm{b}$ is the dominant sensitivity, only the time variation path of $\mathrm{b}$ is analyzed in detail. The first sub-period (2/34-12/54). This period is right after the Great Depression of 1929-1933. The slow recovery pushed the economy to a new peak in the mid of 1937. It is reflected in a high point on the time variation curve of $b$. The curve then falls to the trough for the year of 1938. It may be caused by a brief recession in 1938. The curve gradually reaches a new high in 1942. It is the result of the wartime boom. A few days after the Pearl Harbor bomb on December 7, 1941, the U.S. entered the World War II. The government set high production goals for war goods. According to Campagna (1987), from 1940 to 1943 prices were rising by more than $29 \%$, wages by $45 \%$, and profits by $54 \%$. The stock market sensitivity curve stays at the high level for the wartime. The curve is pulled down by the increase in tax rates on excess profits in 1944 and the postwar inflation and recession in 1948-1949. The inflation caused by the break of the Korean War pulled the curve down further. In the rest years of the first sub-period the curve is rising due to the economic recovery. 
The second sub-period (1/55-12/65). The strong economic expansion in 1955 and 1956 pushed the stock market sensitivity curve to the historically highest level. Then the shape of the curve turns into negative, thanks to the "costpush" inflation and the recessions of 1957-58 and 1960. The slow recovery in the early 1960s and stable prices helped the stock market sensitivity curve restore the height of 1956. Surprisingly, the tax reductions in 1963, 1964, and 1965 could not prevent the decline of the sensitivity curve. Probably, the effect of tax cuts was offset by the increase in the deficits in the balance-of-payments and "the war on poverty."

The third sub-period (1/66-12/72). The overheating and confusing economy in 1966-67, enormous costs of the Vietnam War, and the recession of 1969-70 sent the stock market sensitivity curve to the lowest level since 1939. In order to combat with the unemployment-inflation dilemma, the government established some wage and price control programs in 1971. The initial responses of the sensitivity curve to these programs were obviously positive.

The fourth sub-period (1/73-6/80). During this period the U.S. economy experienced great economic difficulties, the stagflation. That is, high inflations are always combined with high unemployment rates, regardless the business cycle. This unique phenomenon led the sluggish stock market and SMB sensitivities to similar movements (positive correlation).

The fifth sub-period (7/80-12/90). The correlation between the stock market and SMB sensitivities turned back to negative in this period. The SMB sensitivity becomes much more volatile than the stock market sensitivity first time in the entire sample period. Apparently, the business cycle alone could not explain alterations in those two sensitivity curves. The most significant event may be the supply-side tax cut which could have a profound impact on small businesses. The other influential factors for this period were the growing budget and trade deficits.

The sixth sub-period (1/91-12/92). The economic recession in the early 1990's and the fast-growing information technology may be responsible for the big drop in both sensitivity curves over this two-year period.

The seventh sub-period (1/93-12/97). The sound, information technology-driven economy and the inflationsensitive interest rate policy of the Federal Reserve are two key factors in explaining changes in the stock market and SMB sensitivity curves.

Figure 1 indicates that the HML sensitivity, h, is near the zero level for most years in the entire sample period. This is consistent with the trivial OLS coefficient of HML reported in Table 2. There are only four sub-periods in which $\mathrm{h}$ is well above or below the zero level.

The sub-period of 2/34-12/41. The time variation curve of $\mathrm{h}$ starts with a record high point and is getting lower as the economy recovering from the Great Depression. The short-time increase in the curve after 1938 may be the result of the recession of 1938 .

The sub-period of 1/49-12/52. The HML sensitivity curve decreases to a trough, well below the zero level, in 1950. Fama and French (1997) define HML as a "relative distress" measure. The negative HML risk loading for the period mainly reflects the economic boom driven by the Korean War.

The sub-period of 8/73-12/75. This is the most difficult time in the U.S. economic history since the Great Depression. "Stagflation was painfully evident as the worst of all possible worlds--rising prices combined with decreases in output and employment--making a mockery of past macroeconomic solutions to recessionary and inflationary periods" (Campagna, 1987). The negative HML sensitivity over this period may indicate something other than relative distress.

The sub-period of 3/96-12/97. The same puzzle appears in this short period again. While the U.S. economy and capital markets enjoy the best time in history, the HML sensitivity curve of industrial stocks turns into positive and reaches a high level. The result clearly indicates that the interpretation of the HML sensitivity remains an open question.

Overall, it is worthy of note that time variation paths of risk loadings (b, s, and h) largely reflect many different fundamental economic and political changes in different periods. That is, some important changes can effectively explain 
alterations in time variation paths of risk loadings in some periods, while other fundamental changes can be critical explanatory factors for other periods.

\subsection{Verification Of Time Variation Paths Of Risk Loadings}

The OLS results in Table 3 can effectively verify the above seven sub-periods based on the time variation paths of $b$ and s. In the sub-period of $2 / 34-12 / 54, b$ is 0.43 with a t-statistic of 8.60 and $\mathrm{s}$ is 0.23 with a t-value of 2.57 .

The risk loading $\mathrm{b}$ has the highest value (0.75) and $\mathrm{s}$ has the lowest value (0.01) with an insignificant $\mathrm{t}$-statistic of 0.11 in the sub-period of $1 / 55-12 / 65$. As b reduces to 0.37 , s jumps to 0.37 in the sub-period of $1 / 66-12 / 72$. Although the size of s reduces to 0.23 in the sub-period of $1 / 73-6 / 80$, it is still significantly different from zero. Its t-value is 2.09 . In the sub-period of 7/80-12/90, both $\mathrm{b}$ and $\mathrm{s}$ increase their sizes and significance. Over the short period of 1/91-12/92, the OLS results indicate that coefficient $\mathrm{s}$ is greater than $\mathrm{b}$ the first time, $0.60 \mathrm{vs}$. 0.34 . In the following sub-period of $1 / 93-12 / 97, \mathrm{~s}$ shrinks to 0.18 with a t-value of 1.68 , while $b$ increases to 0.44 with a t-value of 4.58 .

In all seven sub-periods the size of $\mathrm{h}$ is small and insignificantly from zero. This is in line with the overall OLS results reported in Table 2. Apparently, the OLS results for sub-periods are completely consistent with the time variation paths of $b$ and s. Similarly, results in Table 3 also provide the OLS evidence for the four sub-periods based on the time variation curve of $h$. In the first sub-period, the magnitude of $h$ is 0.31 with a significant t-statistic. In the second subperiod $h$ has a significant and negative size of -0.41 . The sizable $h(-0.47)$ keeps its high significance level in the following sub-period and turns into positive, 0.59 with a t-statistic of 2.05, in the last sub-period.

\section{Table 3}

\section{Regression Results For Sub-Periods}

$R_{i}-R_{f}=a_{i}+b_{i}\left[R_{M}-R_{f}\right]+s_{i} S M B+h_{i} H M L+e_{i}$

The monthly return series, $R_{i}-R_{f}, R_{M}-R_{f}, S M B$, and HML, are described in Table 1 . The regression $R^{2}$ are adjusted for degrees of freedom.

\begin{tabular}{|c|c|c|c|c|c|c|c|c|c|}
\hline \multirow[b]{2}{*}{ Periods } & \multicolumn{4}{|c|}{ OLS Estimates } & \multicolumn{5}{|c|}{ t-Statistics } \\
\hline & $\mathbf{a}$ & b & $\mathbf{s}$ & $\mathbf{h}$ & $\mathbf{t}(\mathbf{a})$ & $\mathbf{t}(\mathbf{b})$ & $\mathbf{t}(\mathbf{s})$ & $\mathbf{t}(\mathbf{h})$ & $\mathbf{R}^{2}$ \\
\hline $2 / 34-12 / 54$ & 0.04 & 0.43 & 0.23 & 0.13 & 0.17 & 8.60 & 2.57 & 1.48 & 0.40 \\
\hline $1 / 55-12 / 65$ & -0.07 & 0.75 & 0.01 & 0.08 & -0.37 & 14.20 & 0.11 & 0.77 & 0.61 \\
\hline $1 / 66-12 / 72$ & -0.22 & 0.37 & 0.37 & -0.00 & -0.84 & 4.99 & 3.99 & -0.03 & 0.48 \\
\hline $1 / 73-6 / 80$ & -0.61 & 0.47 & 0.23 & -0.01 & -1.89 & 6.39 & 2.09 & -1.06 & 0.49 \\
\hline 7/80 -12/90 & 0.03 & 0.52 & 0.41 & -0.05 & 0.13 & 8.95 & 4.10 & -0.44 & 0.57 \\
\hline $1 / 91-12 / 92$ & -0.07 & 0.34 & 0.60 & 0.28 & -0.13 & 2.16 & 3.41 & 1.35 & 0.40 \\
\hline $1 / 93-12 / 97$ & 0.50 & 0.44 & 0.18 & -0.03 & 1.77 & 4.58 & 1.68 & -0.25 & 0.33 \\
\hline $2 / 34-12 / 41$ & -0.26 & 0.29 & 0.31 & 0.31 & -0.59 & 3.29 & 1.98 & 2.23 & 0.39 \\
\hline $1 / 49-12 / 52$ & 0.27 & 0.62 & 0.18 & -0.41 & 0.69 & 5.11 & 0.81 & -2.69 & 0.35 \\
\hline $8 / 73-12 / 75$ & -0.21 & 0.36 & 0.62 & -0.47 & -0.29 & 2.75 & 2.74 & -1.91 & 0.55 \\
\hline $3 / 96-12 / 97$ & -0.09 & 0.76 & 0.41 & 0.59 & -0.14 & 4.02 & 2.43 & 2.05 & 0.45 \\
\hline
\end{tabular}

\section{Conclusions}

Risk loadings are found to be "time varying" in the literature. This study goes one step further by visibly showing the time variation paths of risk loadings, with the help of the FLS method. The result unambiguously suggests that SMB and HML explain return variation of industrial stocks that is not caught by the beta, the stock market risk loading.

All sub-periods suggested by time variation curves can be verified by the OLS results. Significant structural changes in time variation paths of risk loadings are largely consistent with major economic and political events in the 
U.S. history, such as business cycle, inflation, monetary policy, technology, and war. Some of these events may effectively explain alterations in time variation curves in some periods, while other events can be key explanatory factors for other periods.

The tradeoff relation between measurement and dynamic errors enables the FLS estimates to reach zero measurement errors, if a very small smoothing weight is used. This study provides evidence that the FLS method can generate accurate monthly estimates of factor risk loadings which are of value to corporate financial managers and portfolio managers.

\section{References}

1. Bower, D., R. Bower, and D. Logue. (1984). “Arbitrage Pricing Theory and Utility Stock Returns,” Journal of Finance 39, 1041-1054.

2. Bower, R. and G. Schink. (1994). "Application of Fama-French Model to Utility Stocks," Financial Markets, Institutions and Instruments 3, 74-96.

3. Brown, R.L., J. Durbin, and J.M. Evans. (1975). "Techniques for Testing the Consistency of Regression Relationships Over Time," Journal of the Loyal Statistical Society, Series B, 37, 149-192.

4. Chen, N. (1983). "Some Empirical Tests of the Theory of Arbitrage Pricing," Journal of Finance 38, 13931414.

5. Chen, N., R. Roll, and S. Ross. (1986). “Economic Forces and the Stock Market,” Journal of Business 59, 383403.

6. Elton, E.J., M.J. Gruber, and J. Mei. (1994). "Cost of Capital Using Arbitrage Pricing Theory: A Case Study of Nine New York Utilities," Financial Markets, Institutions and Instruments 3, 46-73.

7. Fama, E., and K. French. (1993). "Common Risk Factors in the Returns on Stocks and Bonds," Journal of Financial Economics 33, 3-56.

8. Fama, E., and K. French. (1995). "Size and Book-to-Market Factors in Earnings and Returns," Journal of Finance 50, 131-155.

9. $\quad$ Fama, E., and K. French. (1997). "Industry Costs of Equity,” Journal of Financial Economics 43, 153-193.

10. Goldenberg, D.H. and A.J. Robin. (1991). "The Arbitrage Pricing Theory and Cost-of-Capital Estimation: The Case of Electric Utilities," Journal of Financial Research 14, 181-196.

11. Kalaba, R., and L. Tesfatsion. (1988). "The Flexible Least Squares Approach to Time-Varying Linear Regression," Journal of Economic Dynamics and Control 12, 43-48.

12. Kalaba, R., and L. Tesfatsion. (1989). “Time-Varying Linear Regression via Flexible Least Squares,” Computers and Mathematics with Applications 17, 1215-1245.

13. Kalaba, R., and L. Tesfatsion. (1990). "Flexible Least Squares for Approximately Linear Systems," IEEE Transactions on Systems, Man, and Cybernetics SMC 20, 978-989.

14. Lintner, J. (1965). "The Valuation of Risk Assets and the Selection of Risky Investments in Stock Portfolios and Capital Budgets," Review of Economics and Statistics 47, 13-37.

15. Lutkepohl, H. (1993). "The Sources of the U.S. Money Demand Instability,” Empirical Economics 18, 729-743.

16. Roll, R., and S. Ross. (1980). "An Empirical Investigation of the Arbitrage Pricing Theory," Journal of Finance 35, 1073-1103.

17. Ross, S. (1976). “The Arbitrage Theory of Capital Asset Pricing,” Journal of Economic Theory 13, 341-360.

18. Sharpe, W. (1964). "Capital Asset Prices: A Theory of Market Equilibrium under Conditions of Risk," Journal of Finance 19, 425-442.

19. Tesfatsion, L., and J. Veitch. (1990). "U.S. Money Demand Instability: A Flexible Least Squares Approach,” Journal of Economic Dynamics and Control 14, 151-173. 